
$=-b 1$

|

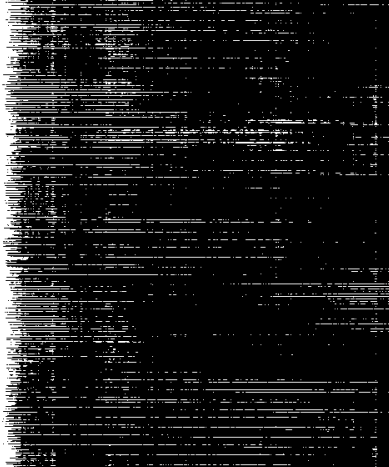

at.

$-$

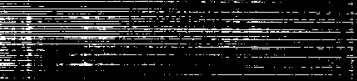

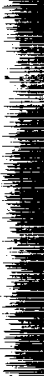

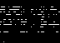

$+$

$+$

$=$

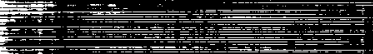

$-(-1+3$

$=$

$+2$

$+2$

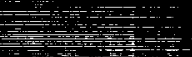

$y+1+4=$

$7+1,+\frac{1}{\square}=$

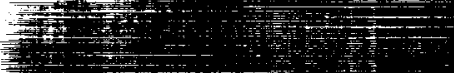

+4)

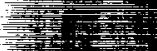

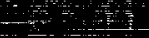
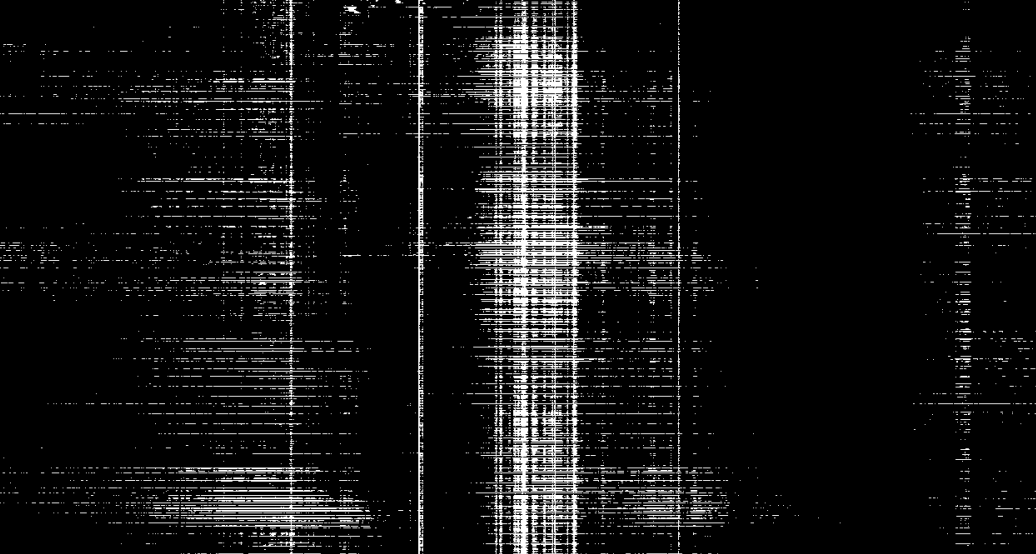

堭

$-2$

14

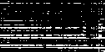

t

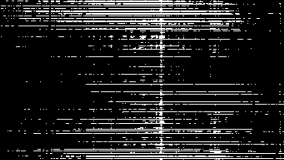

$=$

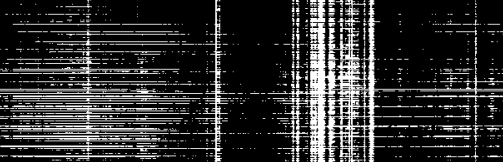

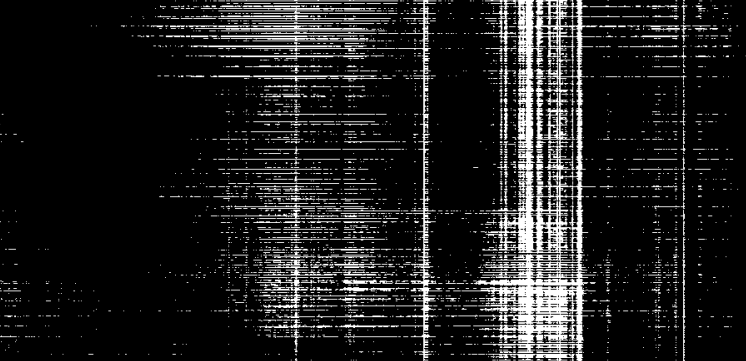

政

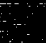

(1)

$=$

논

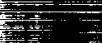

$\sqrt{4}$

$+\ldots$

$-1, \sqrt{4}$

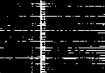

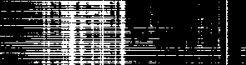

$+\frac{1}{1+3}=$

1)

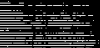
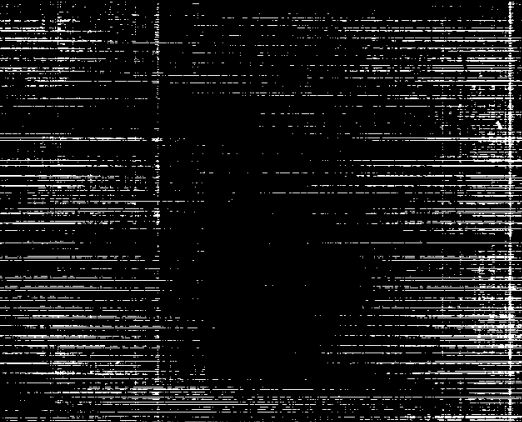

$+1$
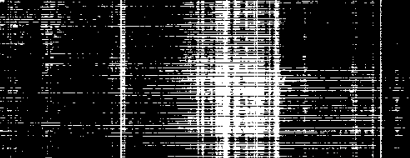

?

(2)

intis

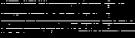

$y=1-1$

$+4$

$=$

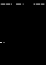

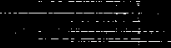

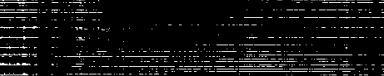

$+4=0$

sit.

$=$

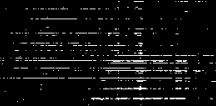

$=-1$

$=-7$

$=$

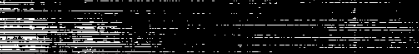

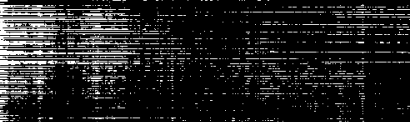

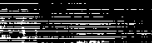

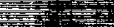

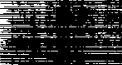

a.

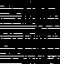

$=$

$-\ldots=2$

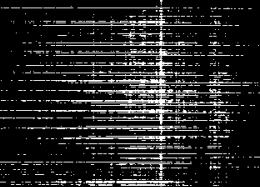

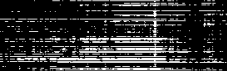

and

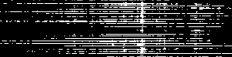

$=$

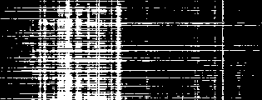

근

औI

1)

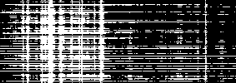

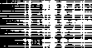

ㄴ.

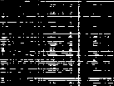

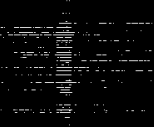

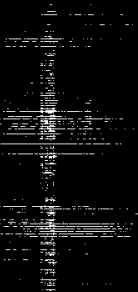

$\frac{2}{2-1}$

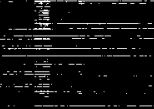

.

$=$

글

政

烈

t率

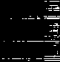

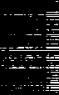

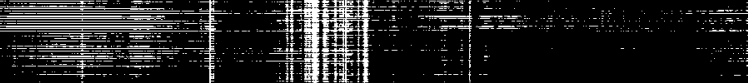

暳

$=0$ 
NASA Technical Memorandum 4142

\section{A Design Procedure for the Handling Qualities Optimization of the X-29A Aircraft}

John T. Bosworth and Timothy H. Cox Ames Research Center Dryden Flight Research Facility

Edwards, California

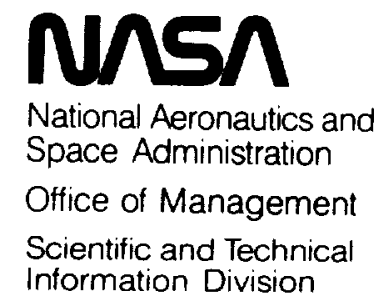

1989 



\title{
A DESIGN PROCEDURE FOR THE HANDLING QUALITIES OPTIMIZATION OF THE X-29A AIRCRAFT
}

\author{
John T. Bosworth* and Timothy H. Cox \\ NASA Ames Research Center \\ Dryden Flight Research Facility \\ Edwards, California
}

\begin{abstract}
A design technique for handling qualities improvement was developed for the X-29A aircraft. As with any new aircraft, the X-29A control law designers were presented with a relatively high degree of uncertainty in their mathematical models. The presence of uncertainties, and the high level of static instability of the X-29A caused the control law designers to stress stability and robustness over handling qualities. During flight test, the mathematical models of the vehicle were validated or corrected to match the vehicle dynamic behavior. The updated models were then used to fine tune the control system to provide fighter-like handling characteristics. A design methodology was developed which works within the existing control system architecture to provide improved handling qualities and acceptable stability with a minimum of cost in both implementation as well as software verification and validation.
\end{abstract}

\section{Nomenclature}

$\begin{array}{ll}e & \text { feedback error }\left(\delta_{p_{c}}-y_{t_{c}}\right) \\ j & \text { square root of }-1 \\ \text { FFT } & \text { fast Fourier transformation } \\ K_{1} & \text { canard feedback gain } \\ K_{2} & \text { normal acceleration feedback gain } \\ K_{3} & \text { pitch rate feedback gain } \\ K_{4} & \text { pilot command gain } \\ K_{p} & \text { Neal-Smith compensator gain }\end{array}$

\footnotetext{
- Member AlAA.

Copyright $(1989$ by the American Institute of Aeronautics and Astronautics, Inc. No copyright is asserted in the United States under Title 17, U.S. Code. The U.S. Government has a royalty-free license to exercise all rights under the copyright claimed herein for Governmental purposes. All other rights are reserved by the copyright owner.
}

$\begin{array}{ll}n_{z_{c}} & \text { compensated normal acceleration } \\ q & \text { pitch rate, deg/sec } \\ q_{c} & \text { compensated pitch rate feedback } \\ s & \text { Laplace transform variable } \\ T & \text { sampling interval, sec } \\ \text { sps } & \text { samples per second } \\ y_{t} & \text { total feedback } \\ y_{t_{c}} & \text { compensated total feedback } \\ z & \text { discrete transform variable } \\ \text { ZOH } & \text { zero order hold } \\ \delta_{c} & \text { canard surface deflection, deg } \\ \delta_{c_{c}} & \text { compensated canard position feedback } \\ \dot{\delta}_{c} & \text { canard surface rate, deg/sec } \\ \delta_{p} & \text { longitudinal stick deflection, in. } \\ \delta_{p_{c}} & \text { compensated pilot longitudinal stick input } \\ \tau_{p 1} & \text { zero for the Neal-Smith compensator } \\ \tau_{p 2} & \text { pole for the Neal-Smith compensator } \\ \omega & \text { frequency, rad/sec }\end{array}$

\section{Introduction}

A design process for improving the pitch axis handling qualities of a flight vehicle was developed for the $\mathrm{X}-29 \mathrm{~A}$. The process is believed to be applicable to all fighter-class airplanes that exhibit a linear response to small amplitude inputs. The method works with the existing flight control system architecture to fine tune the handling qualities of the vehicle. Since the procedure is a fine tuning process, results from flight tests are required to validate or update the mathematical models used in the process.

Control law development for new aircraft follows a natural evolutionary process. The initial mathematical models have a relatively high degree of uncertainty, which requires that the control law design stresses stability and robustness to account for this uncertainty. Consequently, other desired objectives such as perfor- 
mance and handling qualities are often sacrificed to obtain the required robustness, which was true for the $\mathrm{X}-29 \mathrm{~A}$ aircraft. With a highly unstable aircraft, it takes very little control surface deflection to initiate a change in the pitch attitude of the aircraft. The majority of the control power is required to arrest the motion when the desired pitch attitude is achieved. With the modeling uncertainties, the initial control designers reduced the allowed pitch acceleration to ensure that the resulting motion could be controlled and arrested when desired.

After a vehicle is brought to flight test, the mathematical models can be validated or updated to match the flight-test vehicle. Updating the models is not a simple task, however, elimination of gross errors can be accomplished and a degree of validity can be assessed.

After the validation of the math models, the constraint on robustness can be relaxed and the control laws can be adjusted to provide improved handling and performance. However, at that point in the design process it is usually not feasible to make major changes to the control system. Working with the existing control law structure makes relatively minor changes to improve the handling and performance of the vehicle, which is more desirable than creating major architectural changes which are costly and often re-introduce a high level of uncertainty.

The envelope expansion flight-test phase of the $\mathrm{X}-29 \mathrm{~A}$ was completed in August 1987 . During this period, dynamic stability and handling qualities characteristics were investigated throughout the flight envelope. ${ }^{1}$ The envelope expansion process was accomplished with only minor adjustments of the control system gains required. A variety of tasks were flown to provide a qualitative look at the initial handling qualities of the vehicle. These tasks included normal acceleration and pitch attitude captures, formation flying, and air-to-air and air-to-ground tracking. Even with the emphasis on robustness in the design process, the handling qualities of the vehicle were rated as solid level 2. ${ }^{2}$ Pilot comments on the original flying qualities indicated a stick harmony problem and sluggishness in the pitch axis. The longitudinal stick travel was then reduced by a factor of two, while maintaining the same stick force per $g$. This reduction resulted in improved vehicle handling characteristics. However, the question remained as to whether a vehicle with a 35 percent static margin could be driven to perform with the initial accelerations and precise control required of a good level 1 fighter-type aircraft. The goal for the research phase of the flight-test program was to show that fighter-type agility characteristics could be designed into the X-29A.

This paper presents the design process that was developed to improve the handling qualities of the X-29A aircraft. It was a challenge to design the longitudinal control laws for the X-29A vehicle because of the conflicts between designing for stability robustness and good handling characteristics. The challenge was to provide a suitable amount of stability without inhibiting the maneuverability of the vehicle. This issue and, consequently, the longitudinal dynamics are the main focus of the analysis presented here. Both predicted and flight-test results are presented for the new control law design.

\section{Aircraft Description}

The $\mathrm{X}-29 \mathrm{~A}$ is an experimental aircraft designed to demonstrate the integration of several modern technologies into a highly maneuverable aircraft. It is a relatively small, single-seat aircraft powered by a single F404-GE-400 engine. The aircraft dimensions are shown in Fig. 1, and the physical characteristics of the airplane are presented in table 1 .

The vehicle incorporates a forward-swept wing with three surface pitch control and static instability to provide a low-drag configuration. The aircraft wing structure includes aeroelastically tailored graphite-epoxy covers to help provide stiffness to overcome the torsional divergence problems associated with forwardswept wings. The wing has a 5-percent thick supercritical airfoil. Variable camber is provided by full span trailing-edge flaps.

The wing-canard planform results in a high level of instability that has a time-to-double amplitude of approximately $150 \mathrm{msec}$ at the worst case flight condition. Longitudinal control of the aircraft is obtained with active canard, symmetric flap, and strake surfaces (Fig. 1). Lateral-directional motion is controlled by conventional rudder and differential flap deflection.

\section{Flight Control System Description}

The X-29A airplane has a triplex digital flightcontrol system with an analog backup for each channel. The system was designed to be operational after a single sensor failure, and safe after the second failure. The digital control laws are executed at a rate of 
40 samples/sec (sps). Roll, pitch, yaw, and thrust commands are generated by conventional lateral stick, longitudinal stick, rudder pedal, and throttle inputs.

Precise control of the lateral-directional motion of the aircraft was obtained by feeding back roll rate, yaw rate, bank angle, and lateral acceleration. A simplified block diagram of the lateral-directional control system is shown in Fig. 2. For low to moderate angles of attack (less than $20^{\circ}$ ) the lateral-directional dynamic characteristics are relatively conventional and are not presented here.

The primary task of the longitudinal control system is to stabilize the aircraft. In addition to the stabilization task, the control system automatically positions the canards, flaps, and strakes to minimize drag in trimmed flight. A simplified diagram of the primary digital longitudinal control laws is shown in Fig. 3. Three feedback signals (pitch rate, normal acceleration, and canard position) are used to stabilize the aircraft, however, as can be seen from the block diagram, they are summed at one point ( $y_{t_{c}}$ on Fig. 3). This means that the longitudinal axis can be treated as a single-input, single-output system with one welldefined open-loop transfer function. This allows for the use of gain and phase margins to assess the stability of the system. ${ }^{3}$ A more complete description of the flight control system can be found in Ref. 4 .

\section{Design Technique}

It was a challenge to increase the responsiveness of the X-29A vehicle while maintaining precise controllability. A production aircraft would require good handling qualities throughout the flight envelope. The X-29A handling qualities improvements were limited to a specific part of the flight envelope because of the fixed amount of test time available. Two design points in the X-29A flight envelope were chosen which demonstrated the improved handling. The design points corresponded to break points in the longitudinal gain tables. Therefore, changing the gains at the two selected break points affected an area of the flight envelope that was large enough to allow for normal maneuvering without departing from the affected region of the change.

The process used to provide improved handling of the X-29A vehicle involved four steps:

1. Selection of the design goals,

2. Selection of the design variables,
3. Definition of the cost function, and

4. Calculation of the cost function.

These steps are discussed in more detail in the following sections.

\section{Selection of Design Goals}

The Neal-Smith analysis provides a good quantitative method for assessing the handling qualities of a vehicle. ${ }^{5}$ Unlike lower order equivalent systems analysis, the Neal-Smith technique applies to systems that do not exhibit classical second order behavior. In addition there is no ambiguity introduced by the "goodness" of the fit of the higher order system to a low order match. The Neal-Smith technique takes the longitudinal stick position to pitch rate (or attitude) transfer function, and closes the loop around it with a compensator. The compensator consists of a lead-lag filter with a gain and a time delay (Fig. 4). The compensator provides a very simple model of the pilot function. The compensator is not intended to model the dynamics of a pilot accurately, rather, it is used as an indicator to measure the amount of compensation that is required to obtain certain desired closed-loop characteristics (ideal tracking). The relative workload of the pilot is measured in terms of the amount of lead that is required, and the peak magnitude of the compensated closed-loop frequency response. The peak magnitude and pilot lead define a point on the Neal-Smith plane, which has experimentally defined level 1,2 , and 3 handling qualities boundaries.

A validated linear model was used to calculate the pitch rate due to longitudinal stick position frequency response $\left(\frac{q}{\delta_{p}}\right)$ at the two design flight conditions. These frequency responses were used to calculate the two points shown on the Neal-Smith plane in Fig. 5. For one of the design points, flight data from a frequency sweep was available to validate the model. The Neal-Smith criterion indicates a relatively large amount of lead required of the pilot to obtain the desired tracking performance. This correlates well with the pilot's desire for increased pitch responsiveness.

The design objective to obtain quicker pitch response without adversely affecting the controllability is rcached by reducing the amount of lead required by the pilot and maintaining a low, closed-loop resonant peak. This design objective corresponds to moving the points on the Neal-Smith plane to the left into the center of the level 1 region. The design goal for the X-29A aircraft was to reduce the amount of lead required of 
the pilot, while maintaining acceptable stability margins and control surface activity.

\section{Selection of Design Variables}

Choosing appropriate design variables is important in developing an efficient design algorithm. A sufficient number of variables is required to provide enough flexibility to meet the design goals. However, if too many variables are chosen the number of possible combinations increases significantly, which results in a high cost for computing the "optimal" solution and the resulting design change may be more complicated than required. An increased cost in software verification and validation is the result.

It is desired to "fine tune" the flight control system to provide improved handling qualities without drastic changes in control system architecture. If the fine tuning can be accomplished with gain changes only, the cost in terms of software verification and validation time will be reduced. If the fine tuning process requires additional dynamic elements (such as a leadlag or washout filter) the poles or zeros of the filter can bc used as design variables. Adding dynamic elements often significantly increases the cost of implementing the change.

The design variables should be chosen so that their effect on the system can be accurately predicted. For cxample, on the X-29A there are three control surfaces and three feedback variables which are used to control the longitudinal motion. A designer could allow the gains on each of the control surfaces to vary, which would change the way the forward-loop command is proportioned to the three surfaces. This choice of design variables would require precise knowledge of the individual control surface effectiveness derivatives. Because of the multiple active control surfaces that move in phase with each other, the contribution of each individual surface to the resulting motion of the aircraft could not be directly measured. This choice of design variables would involve some risk.

The design variables used for the X-29A were the gains on each of the three feedbacks as well as the gain on the pilot command. The gain on the pilot command was allowed to vary only to maintain the same stick force per $g$ since the design goal was to improve the dynamic response of the vehicle, not to change the stcady-state response. The four design variables provided enough flexibility to provide improved handling with adequate stability, and the implementation of the change required only a small software change. For the $\mathrm{X}-29 \mathrm{~A}$, in-flight measurements of the three feedbacks as well as the feedback error ( $e$ on Fig. 3 ) were available for analysis. The contribution of each of the feedbacks to the overall system behavior was directly measurable. Thus, as long as the new gains did not drive the system to nonlinear behavior, the effect of each of the feedback gains was known to a high degree of certainty.

\section{Definition of Cost Function}

The cost function is a numerical value that indicates how well a particular design meets the design goals. The lower the cost function value, the closer the design comes to meeting the design requirements. For the X-29A, improvement of the vehicle handling qualities was desired without losing too much stability or demanding too much surface activity.

The desire for improved handling qualities corresponds with moving the points on the Neal-Smith plane to the left into the center of the level 1 region. This can be expressed mathematically by finding the combination of design variables that define a point on the Neal-Smith plane which has a minimum distance from the desired point in the center of the level 1 region. The point defined as the desired Neal-Smith criterion was nominally $0.0 \mathrm{~dB}$ and $10.0^{\circ}$ (sce Fig. 5). This point was casily changed to allow the designer to assess the trade-offs between the design goal and the design constraints.

The stability margin constraint was met by selecting a minimum level of gain and phase margin which, if not met, added a large value to the cost function. The values of the minimum acceptable stability levels were nominally $6.0 \mathrm{~dB}$ and $40.0^{\circ}$. This constraint could be changed by the designer to allow quick assessment of design trade-offs.

The requirement for reasonable surface activity can be achieved by calculating the stick-to-surface deflection (or rate) and putting limits on the gain peak or requiring a certain amount of gain roll off. This constraint is similar to imposing restrictions on the bandwidth of the system. This requirement will also tend to eliminate the control system designs that would cause aeroservoelastic instabilities. For the X-29A design, a limit was placed on the maximum amplitude of the canard rate due to longitudinal stick position frequency response $\left(\frac{\dot{\delta}_{c}}{\delta_{p}}\right)$. Although this constraint does not guarantee there will be no rate limiting during untrimmed or higher $g$ flight, it will tend to eliminate designs with severe rate limiting problems. 
The cost function, a real valued scalar, was defined as follows:

cost function $=$ resonant peak error

$$
\begin{aligned}
& +\frac{\text { pilot compensation error }}{\text { scale factor }} \\
& + \text { constraint penalty }
\end{aligned}
$$

where:

$$
\begin{array}{ll}
\text { resonant peak error }= & \begin{array}{l}
\text { the distance between the } \\
\text { achieved resonant peak } \\
\text { and the desired resonant } \\
\text { peak }(0.0 \mathrm{~dB})
\end{array}
\end{array}
$$

pilot compensation error $=$ the distance between the achieved pilot compensation and the desired amount of pilot compensation $\left(10.0^{\circ}\right)$

constraint penalty $=$

10000.0 if the stability margin constraint was violated, 10000.0 if the surface activity constraint was violated, 0.0 otherwise

scale factor $=\quad 7.0$, which is commonly used to compensate for the difference in magnitude of the units of $\mathrm{dB}$ and deg (this value is usually used in lower order equivalent systems matching)

\section{Calculation of Cost Function}

For this particular design process, the design goals must all be calculated as a function of the frequency response of the system. With the cost function defined in terms of frequency domain transfer functions, block diagram algebraic manipulations can be used to provide a quick and efficient means of calculating the various required frequency responses. ${ }^{6}$ The cost function is determined from three different transfer functions; the closed-loop stick-to-pitch rate transfer function $\left(\frac{q}{\delta_{p}}\right)$ (for determining the Neal-Smith criterion), the open-loop transfer function ( $\frac{y_{t_{c}}}{e}$ ) (for calculating stability margins (see Fig. 6)), and the stick-to-canard rate transfer function $\left(\frac{\dot{\delta}_{c}}{\delta_{p}}\right)$ (for limiting surface activity). These three frequency responses were obtained from algebraic manipulation of subsystem frequency responses and the design variables as follows:

$$
\begin{aligned}
& \frac{q}{\delta_{p}}=\frac{K_{4} \frac{\delta_{p_{c}} q}{\delta_{p} e}}{\left[1.0+\frac{y_{t_{c}}}{y_{t}}\left(K_{1} \frac{\delta_{c_{c}}}{\delta_{c}} \frac{\delta_{c}}{e}+K_{2} \frac{n_{z_{c}}}{e}+K_{3} \frac{q_{\varepsilon} q}{q}\right)\right]} \\
& \frac{y_{t_{c}}}{e}=\frac{y_{t_{c}}}{y_{t}}\left(K_{1} \frac{\delta_{c_{c}}}{\delta_{c}} \frac{\delta_{c}}{e}+K_{2} \frac{n_{z_{c}}}{e}+K_{3} \frac{q_{c}}{q} \frac{q}{e}\right) \\
& \frac{\dot{\delta}_{c}}{\delta_{p}}=\frac{K_{4} \frac{\delta_{p_{c}}}{\delta_{p}} \frac{\delta_{c}}{e} s}{\left[1.0+\frac{y_{t_{c}}}{y_{t}}\left(K_{1} \frac{\delta_{c_{c}}}{\delta_{c}} \frac{\delta_{c}}{e}+K_{2} \frac{n_{n_{c}}}{e}+K_{3} \frac{q_{c} q}{q}\right)\right]}
\end{aligned}
$$

Figure 7 shows a block diagram that defines the subsystem transfer functions. The subsystem frequency responses were calculated and stored as vectors of complex numbers which were a function of frequency $(\omega)$. These were obtained from the $s$ and $z$ plane descriptions of the subsystem transfer functions by the following substitutions:

$$
\begin{aligned}
& s=j \omega \\
& z=\cos (\omega T)+j \sin (\omega T)
\end{aligned}
$$

The sample and hold devices were modeled with the approximation of a zero order hold:

$$
\mathrm{ZOH}=\frac{1-e^{-s T}}{s T}
$$

The aircraft acrodynamic frequency responses were obtained from standard linear equations of motion of the airframe at cach of the two flight conditions.

In the initial setup of the problem, the frequency responses of the subsystem transfer functions are calculated and stored in memory. For a given set of design variables, the closed-loop, open-loop, and stickto-canard rate frequency responses, and consequently the cost function can be quickly computed. For each design iteration the cost function is obtained very quickly by algebraic manipulation of the subsystem frequency responses and the design variables. Calculating the cost function quickly is important for an iterative search for an optimal set of design variables, since many combinations of design variables need to be cvaluated. The subsystem transfer functions should be chosen to leave a minimum amount of calculation required to evaluate each combination of the design variables.

There are many computer algorithms available that will minimize a cost function by varying design 
parameters. $^{7}$ A gradient search algorithm was used for the X-29A design problem. The stability and control surface activity design constraints introduced a step discontinuity in the cost function. Since the minimization algorithm uses numerical derivatives to calculate the gradients, a smooth, continuous function was not required for convergence to a solution. However, the problem is highly nonlinear and many local minima exist. A unique global minimum is not guaranteed to exist. It was found that reasonable solutions could be obtained with the proper selection of starting conditions of the algorithm. An interactive program was developed which allowed the user to control the starting gains, the range of variation of each gain, and the cost function constraints. Thus by varying the starting conditions and design goals and using quick local scarches, the user could iterate to a reasonable solution fairly quickly.

The flight-measured frequency responses could in theory be used in the design process. In practice, the minimization of the cost function is adversely affected by scatter in the data. A smooth, noise-free frequency response, such as one calculated from a linear model that has been validated by flight test, provided better convergence of the numerical gradient search algorithm.

\section{Validation of the X-29A Mathematical Model}

For the handling qualities re-design, accurate modcls of the vehicle are required. In general, parameter estimation techniques are used in flight test for model verification. Aerodynamic stability and control derivatives are extracted from time history data. These derivatives are then compared with the wind-tunnel predictions which were used to develop the simulation models. In the case of the X-29A longitudinal axis, the presence of multiple active control surfaces and the high degree of static instability made it difficult to obtain the individual control effectiveness derivatives. In addition, the high-gain full-authority flight-control system itself provides a significant amount of complexity that must be modeled correctly. The handling qualities re-design procedure discussed herein requires a verified frequency response which accurately represents the dynamics of the entire system, including both the aerodynamics and the flight-control system.

It was found that a fiftieth-order model was adequate for predicting the dynamic behavior of the X-29A in the flight regime that would be affected by the design change. The aerodynamic model was composed of a fourth-order rigid body model that did not include the higher frequency structural modes. The other states were made up of sensors, notch filters, prefilters, actuators, and control system dynamics.

A time history comparison of the linear model and vehicle responses to pilot inputs is shown in Fig. 8. From the time history data it can be seen that the model is fairly close to the actual vehicle performance. A more critical look at the data shows small differences that may or may not be important. It was found, however, that with pilot-generated frequency sweeps and fast Fourier transformation (FFT) techniques, a direct measurement of the subsystem frequency responses could be obtained (Figs. 9-11). The transfer functions from $e$ to the three feedback gains which were used by the linear model, were incorporated into the design algorithm. The frequency responses derived from flight data provided a direct validation of the transfer functions which were used in the design process. Because the linear model is used for fine tuning the control system, a high degree of accuracy is required. If significant differences between the model and flight data are present, the transfer functions should be adjusted to account for the differences.

\section{Nonlinear Simulation Validation of New Design}

The design process works with a linear representation of a nonlinear system. It then becomes important to execute the new control laws on a nonlincar simulation to ensure that the new gains do not drive the system to nonlinear behavior. When implemented on a nonlinear simulation, the new gains verified the quicker pitch acceleration, but the new system showed a greater tendency to rate limit the surfaces during large amplitude maneuvering. An extensive amount of testing was done to ensure that the airplane would not depart into a tumble mode because of control surface rate limiting during aggressive mancuvers.

Another important consideration of the design process is that the design algorithm provides a point by point optimized design at each specific flight condition. When the new gains are incorporated into a gain schedule, the system behavior must be assessed between the design points to ensure that the resulting interpolated gains also provide desired system behavior. A practical design can be obtained by constraining the amount of gain variation allowed between break 
points. After nonlinear simulation, constraints were added to the design algorithm to reduce the range of gain values to reasonable numbers.

The nonlinear simulation also showed the performance of the design during rapid transition between the design points. If the gains are too sensitive to flight condition, problems can occur when the gain updates lag behind the changes in aerodynamic conditions. The simulation also provides an assessment of the failure tolerance of the new design. None of these concerns can be addressed with linear simulation.

Pilot-qualitative comments and evaluation of the nonlinear simulation were not significant factors in evaluating the improved control system. The simulation was fixed base with a very limited visual system and thus not suitable for fine-tuning handling characteristics.

\section{Results}

\section{Predicted Characteristics}

Figure 12 shows the Neal-Smith criterion predicted by the linear model with the optimized flight-control system gains. The design goal of $10.0^{\circ}$ of lead and $0.0 \mathrm{~dB}$ resonant peak was not achieved because of the design constraints, however, the amount of pilot lead was reduced by approximately 50 percent. The closedloop resonant peak achieved by the modified gains was below $1.0 \mathrm{~dB}$ for each of the design points. This resulted in Neal-Smith criteria which were well within the level 1 region of the Neal-Smith plane.

The design process showed a definite trade-off between the design constraints and the achievable NealSmith criterion. The modified design gains demonstrated a slightly reduced level of stability margin (Fig. 13) and increased surface activity. Figure 14 shows a comparison of the step response of the linear model with the old and new gains. It can be seen that the new gains provide increased initial pitch accelerations in part by allowing the pitch rate to overshoot the final value. The low value obtained for the closedloop resonant peak, however, indicates that even with the open-loop overshoot the response in a closed-loop tracking task is controllable and predictable. Figure 14 also shows the increased level of surface activity required to obtain the crisper pitch response.

\section{Flight Test of New Design}

Figure 12 shows that the Neal-Smith criteria predicted by the linear model were verified by flight test. In-flight measured frequency responses indicated points on the Neal-Smith plane with approximately $0.0 \mathrm{~dB}$ of resonant peak and $20.0^{\circ}$ of lead required by the pilot. In general, the pilot comments indicated a marked improvement in the performance of the new flight-control system.

"The aircraft pitch response was instinctively correct. [The pilot] was able to control the pitch axis in fine tracking without consciously providing compensation. The initial accelerations were comparable to [other fighter class airplanes]. [The pilots] no longer had to rcduce the aggressiveness of the tasks due to lags in the response."

Figure 15 shows the response of the aircraft to a step input and how it compares to the linear model. The step response verifies that the initial pitch accelerations which were predicted by the linear model were obtained in flight. Despite the pitch rate overshoot, the closed-loop pilot plus aircraft response was very predictable and controllable as was predicted by the NealSmith analysis. The pilot comments indicated that

"having the initial pitch acceleration gave [them] something to work with so that [they] could cause quick, precise changes in tight tracking tasks. Whereas, with the old gains the sluggish response caused [them] to consciously back off on the task to compensate for lags in the aircraft."

Despite the validation of the linear and nonlinear models and the extensive analysis performed, the phase margin with the new gains measured from flight data was significantly less than what was predicted from the linear model (see Fig. 16). The difference is suspected to be a result of the strake flap actuator rate limiting. Although the strake rate limiting had very little effect on the three forward-loop frequency responses (Figs. 17-19), the seemingly insignificant differences were enough to cause a large change in the phase margin. It is suspected that the differences seen on the open-loop frequency response measurements are the result of the difference between summing in-phase or out-of-phase feedbacks. The nonlinear simulation was not accurate enough to predict this occurrence.

The Neal-Smith criteria obtained from the flighttesting of the new design shows that the desired ob- 
jective was achieved because the points on the NealSmith plane were moved toward the center of the level 1 region (Fig. 12). (The effects of the strake rate limiting were outside the frequency range of pilot interest.) The crisper pitch response was obtained with higher levels of surface activity. The new system approached but did not exceed the maximum capability of the system.

\section{Concluding Remarks}

The design methodology outlined in this paper provides a practical means for improving the handling qualities of a flight vehicle without excessive system re-design. The method provided a 100 percent increase in the pitch acceleration of the X-29A vehicle with precise control. The method allows the designer to work with the existing control system architecture to finetune the handling qualities of the aircraft. The iterative procedure allows the designer to quickly assess tradeoffs between design goals and constraints.

The method is a lincar analysis technique, however, and the effects of nonlinear elements should be studicd on a nonlinear simulation. The method requires accurate transfer function descriptions of the vehicle. These can be obtained by using flight data to validate or update linear models of the vehicle. Fast Fourier transformation (FFT) techniques can be used to measure subsystem frequency responses which are required for the design method. This provides a means for incorporating flight-test results into the design process.

The final design for the $\mathrm{X}-29 \mathrm{~A}$ resulted in a lower phase margin than was predicted. This was caused by a sensitivity of the system to rate limiting which had been observed at other flight conditions with the original control system gains, but had not been completely understood. The rate limiting problem occurred at frequencies higher than the range used by a pilot in handling qualities tasks. The experiment showed that a vehicle with the high level of static instability of the $X-29 A$ can be made to perform with accelerations comparable to those of existing state-of-the-art aircraft, however, it should be noted that the maximum $g$ capability $(6.4 \mathrm{~g})$, and the minimum accepted stability margin levels of the X-29A were significantly less than those required by an operational production fighter aircraft.

This design methodology could be used to optimize the longitudinal handling qualities of any existing fighter-class airplane that exhibits a linear response to small amplitude inputs. The cost of the resulting re-design can be reduced by limiting the extent of the change to the minimum required to obtain the desired results. This is a practical approach that has been shown to work on a real problcm.

\section{References}

${ }^{1}$ Gera, J., and Bosworth, J.T., Dynamic Stability and Handling Qualities Tests on a Highly Augmented, Statically Unstable Airplane, NASA TM-88297, 1987.

2 "Military Specification - Flying Qualitics of Piloted Airplanes," MIL-F-8785C, Nov. 1980.

${ }^{3}$ Bosworth, J.T., and West, J.C. , "Real-Time OpenLoop Frequency Response Analysis of Flight Test Data," AIAA-86-9738, Apr. 1986.

${ }^{4}$ Whitaker, A., and Chin, J., "X-29 Digital Flight Control System Design," AGARD-CP-384, presented at the AGARD Symposium on Active Control Systems, Toronto, Canada, Oct. 1984.

${ }^{5}$ Neal, T.P., and Smith, R.E., An In-Flight Investigation to Develop Control System Design Criteria for Fighter Airplanes, Vol. I, AFFDL-TR-70-74, Dec. 1970.

${ }^{6}$ Friedland, B., Control System Design: An Introduction to State-Space Mcthods, McGraw-Hill Book Co., New York, 1986.

${ }^{7}$ IMSL Library Reference Manual, 8th ed., Vol. II, IMSL LIB-0008, IMSL, Inc., Houston, 1980. 
Table 1. X-29A physical characteristics.

\begin{tabular}{ll}
\hline \hline Wing span & $27.2 \mathrm{ft}$ \\
Wing area & $185 \mathrm{ft}^{2}$ \\
Wing leading-edge sweep (forward) & $29.3^{\circ}$ \\
Mean aerodynamic chord & $7.2 \mathrm{ft}$ \\
Vehicle empty weight & $14,000 \mathrm{lb}$ \\
Maximum fuel capacity & $4,000 \mathrm{lb}$ \\
Maximum thrust & $16,000 \mathrm{lb}$ \\
Canard area & $37 \mathrm{ft}^{2}$ \\
\hline
\end{tabular}

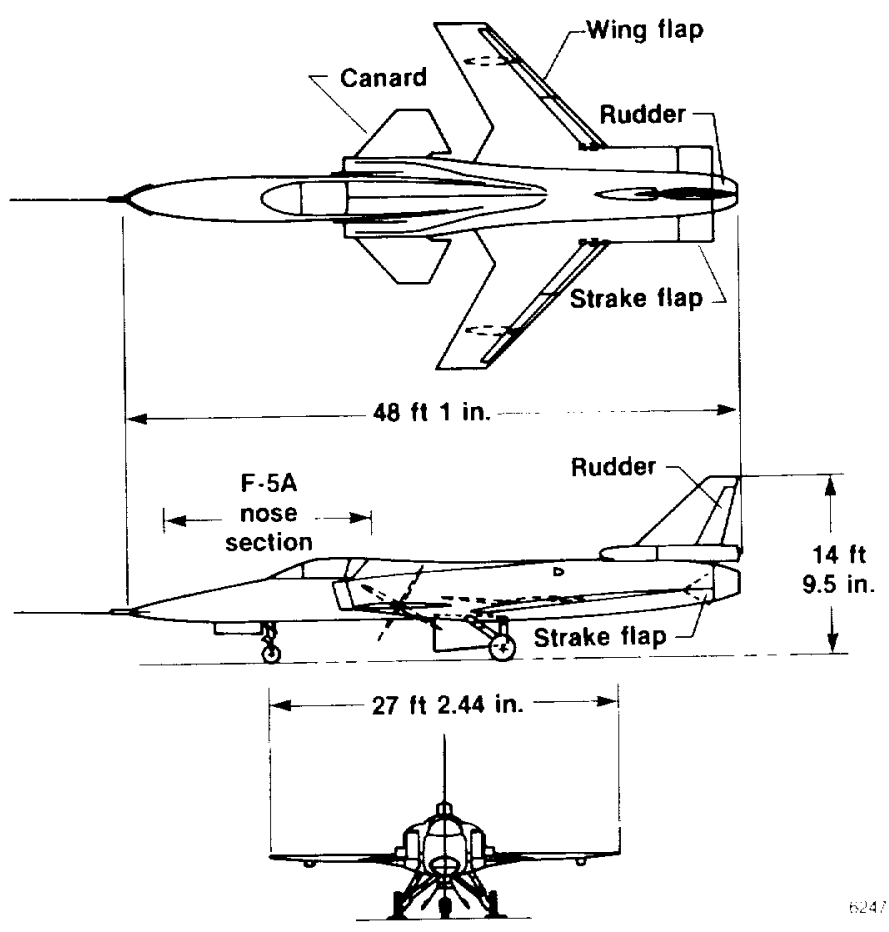

Fig. 1 X-29A airplane.

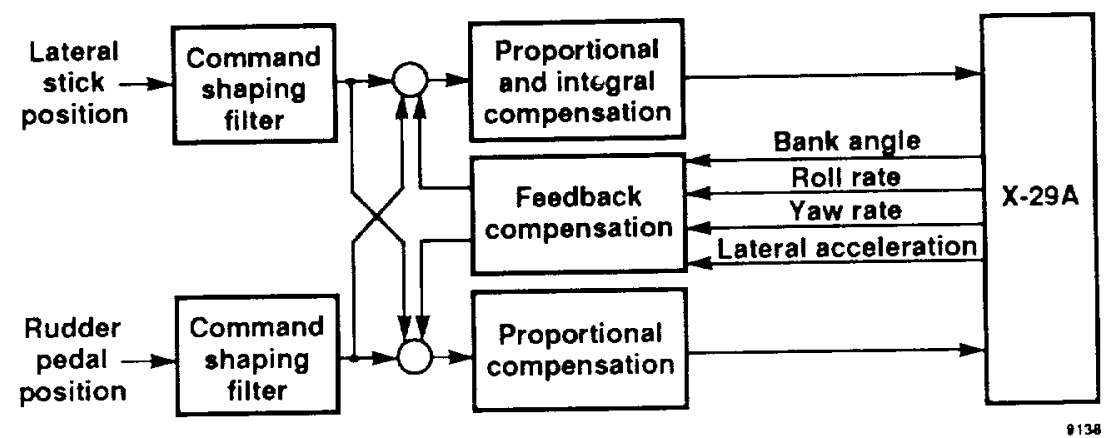

Fig. 2 Simplified lateral-directional control law block diagram. 


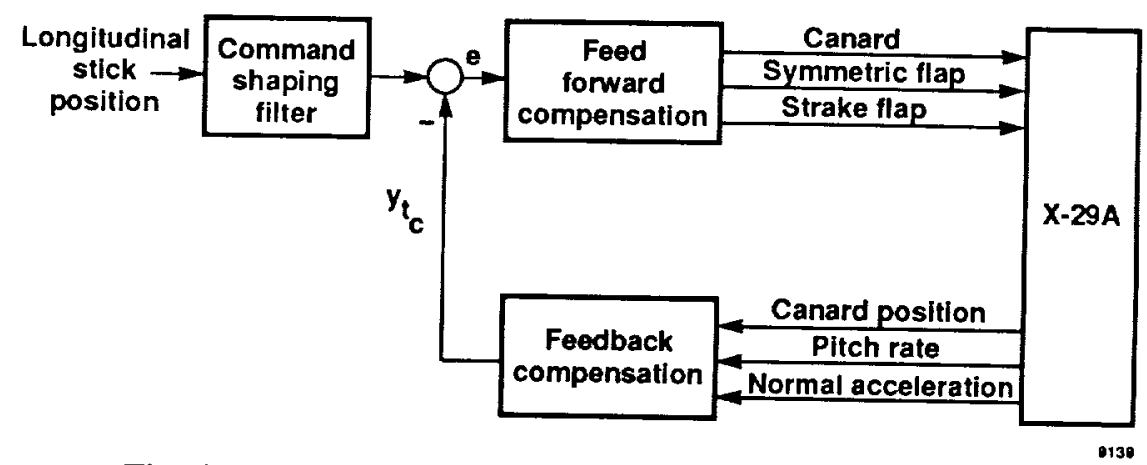

Fig. 3 Simplified longitudinal control law block diagram.

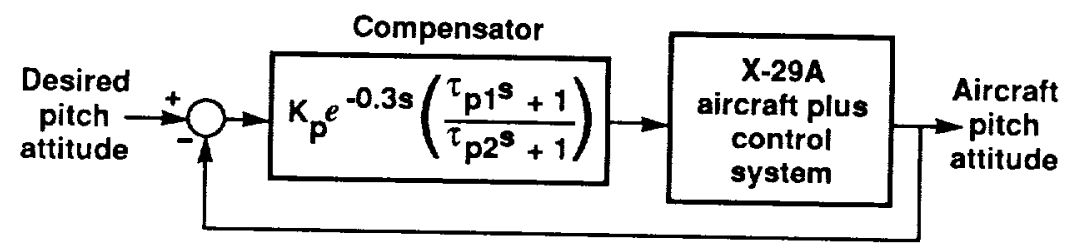

Fig. 4 Block diagram of closed-loop pitch attitude tracking task.

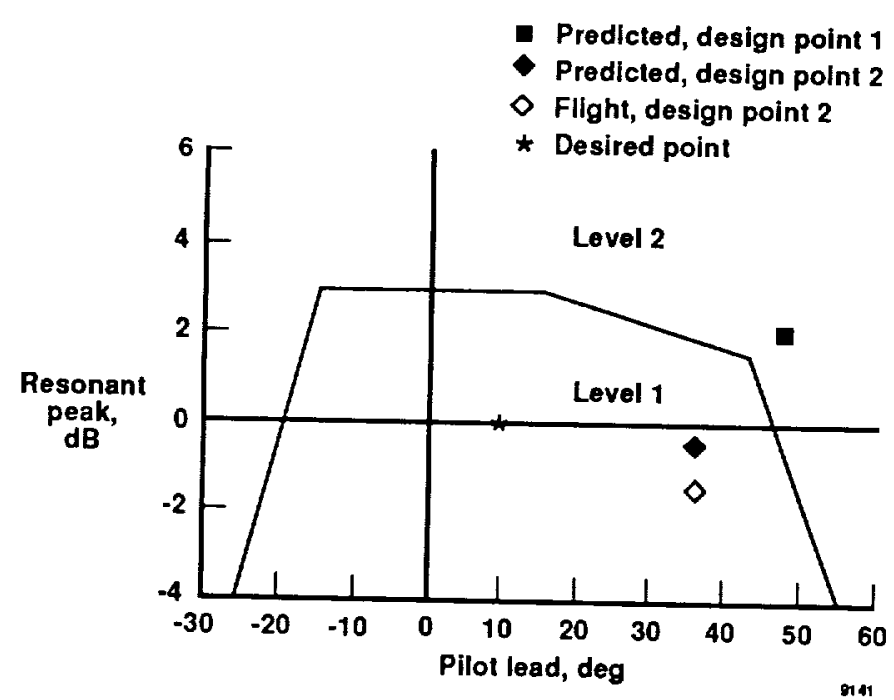

Fig. 5 Neal-Smith analysis on original gains comparing predicted and flight test results. 


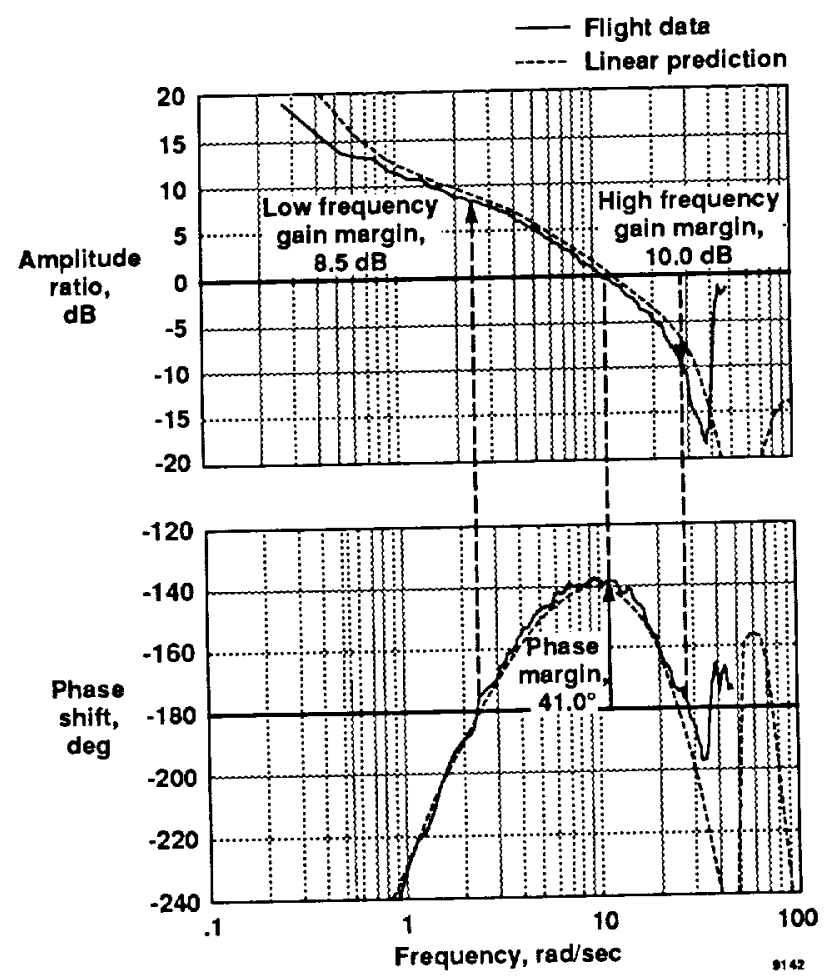

Fig. 6 Open-loop frequency response transfer function.

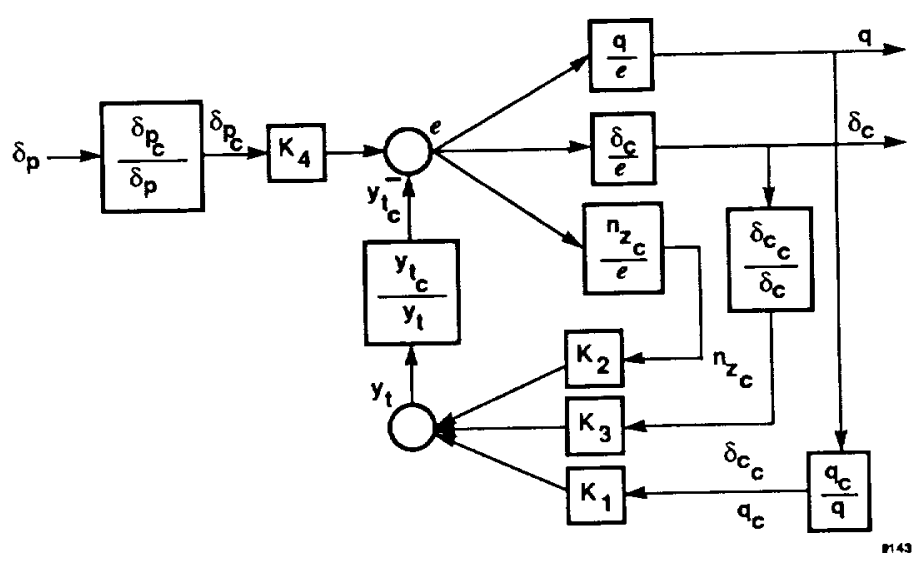

Fig. 7 Longitudinal control law block diagram showing subsystem transfer functions. 

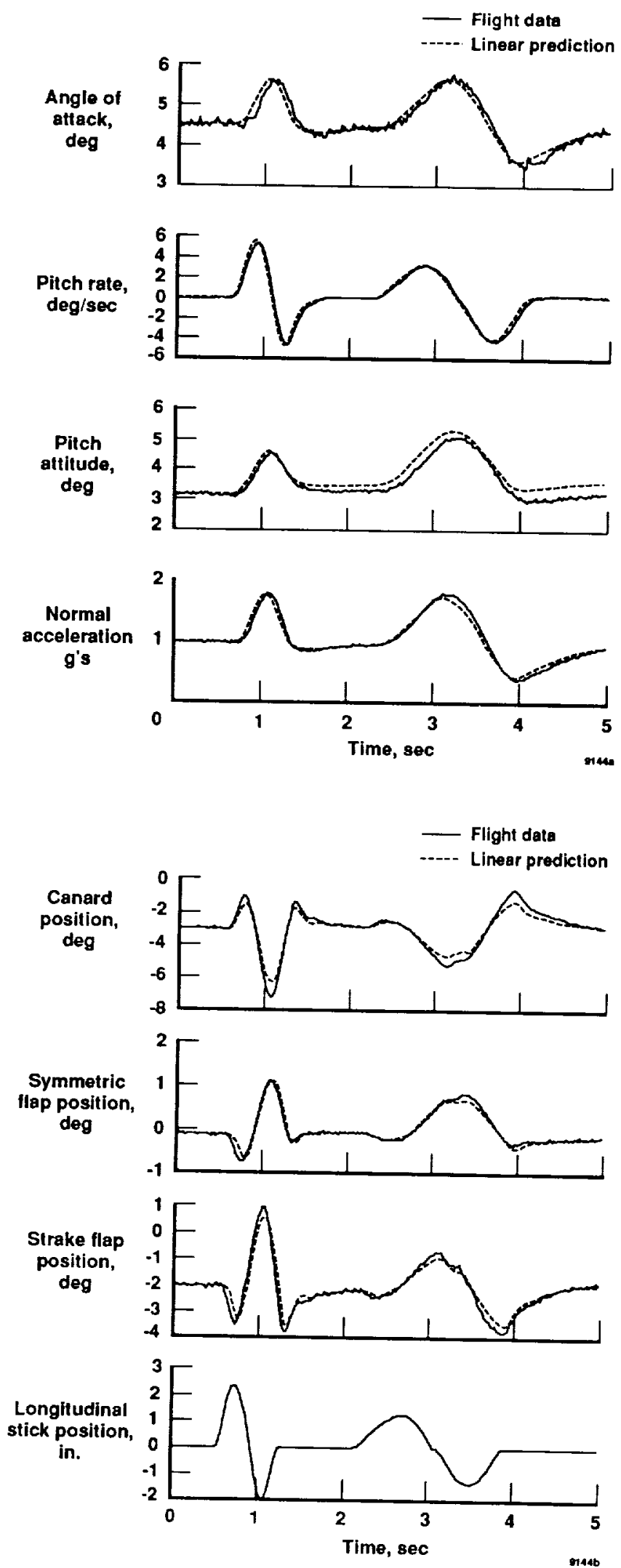

Fig. 8 Response of vehicle to pitch doublet compared with linear model. 


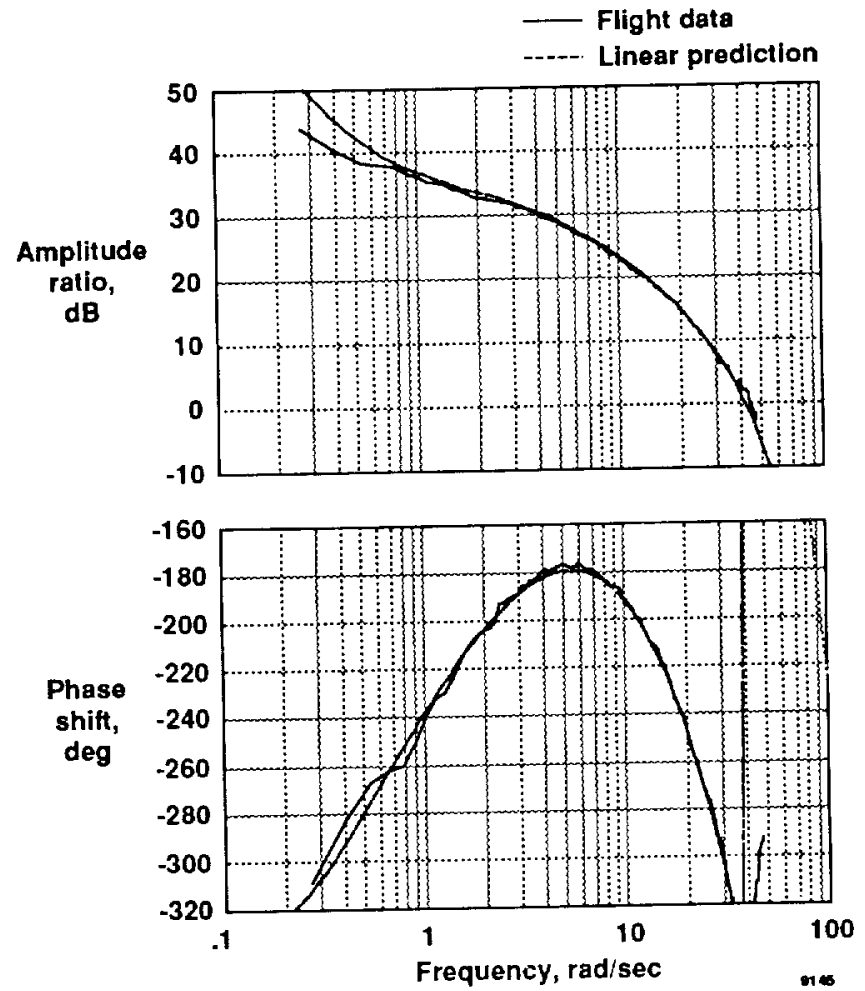

Fig. 9 Pitch rate due to $e$ transfer function.

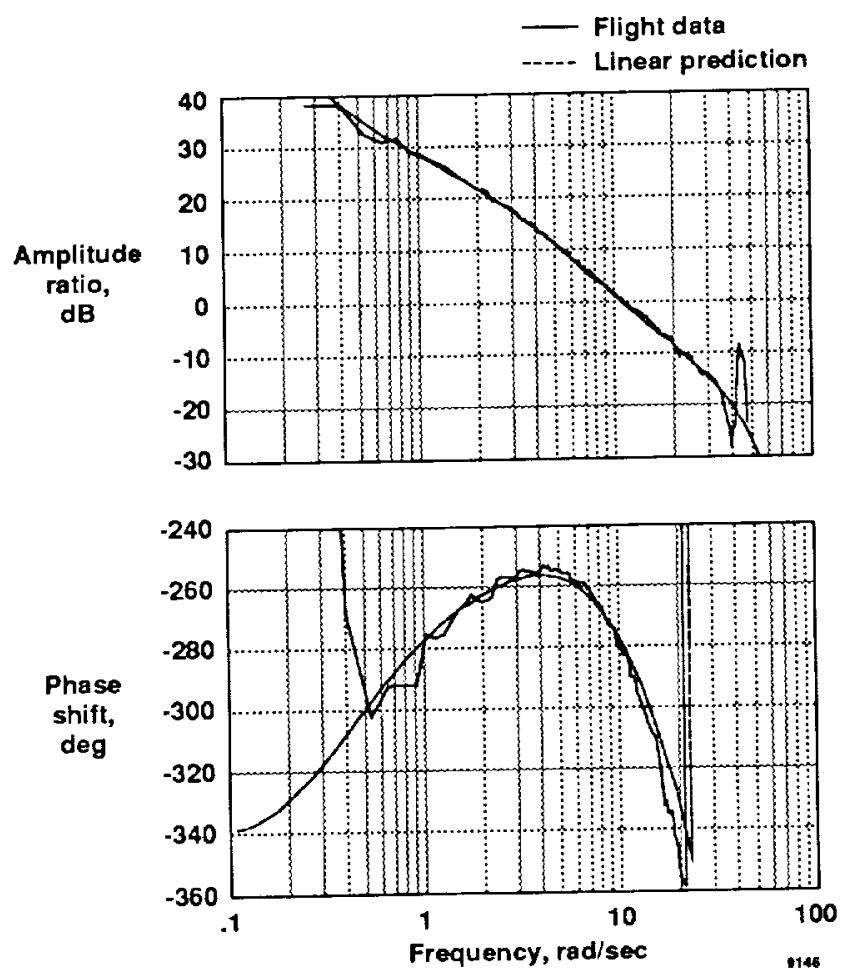

Fig. 10 Normal acceleration duc to e transfer function. 

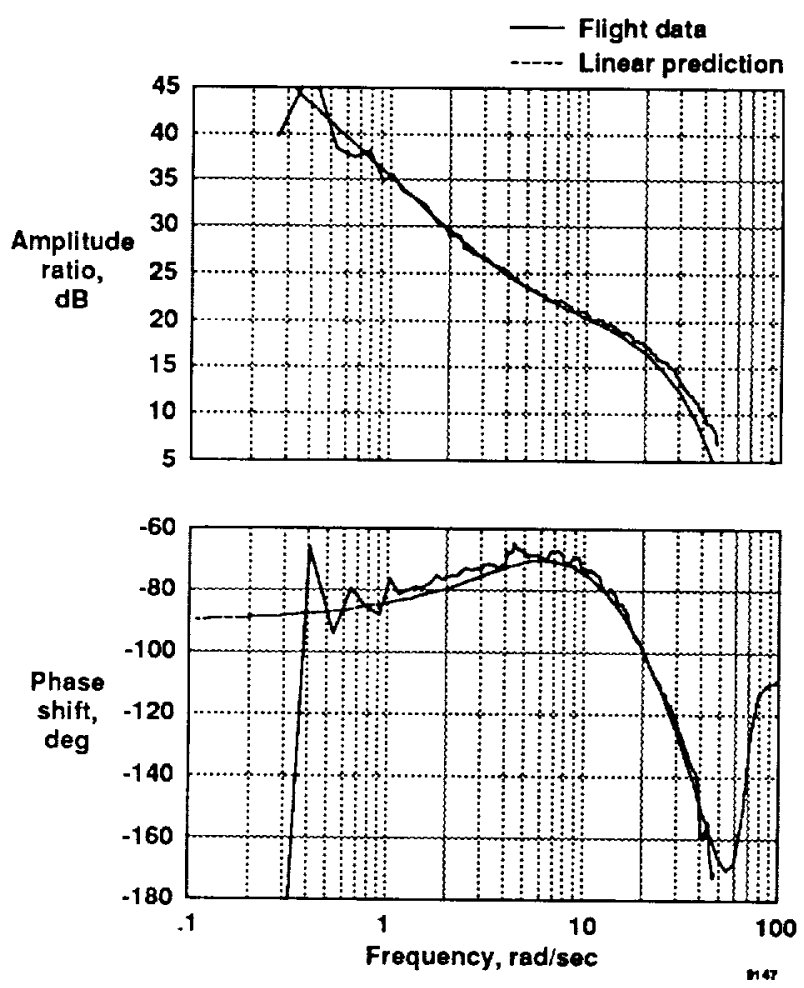

Fig. 11 Canard position due to $e$ transfer function.

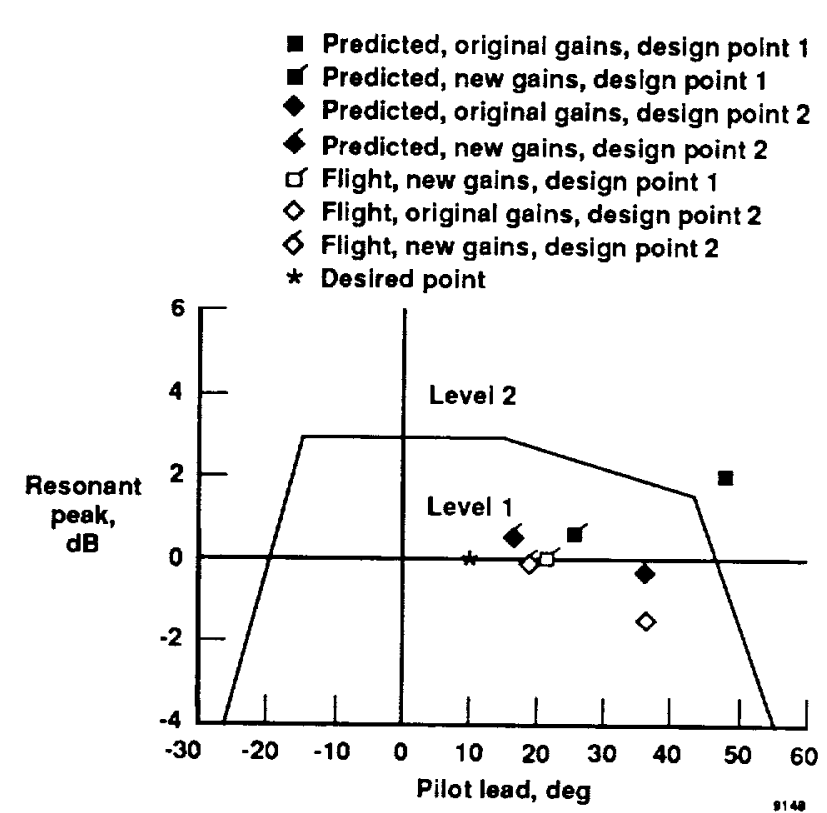

Fig. 12 Neal-Smith analysis comparing the modified gains with the original gains for both predicted and flight test results.
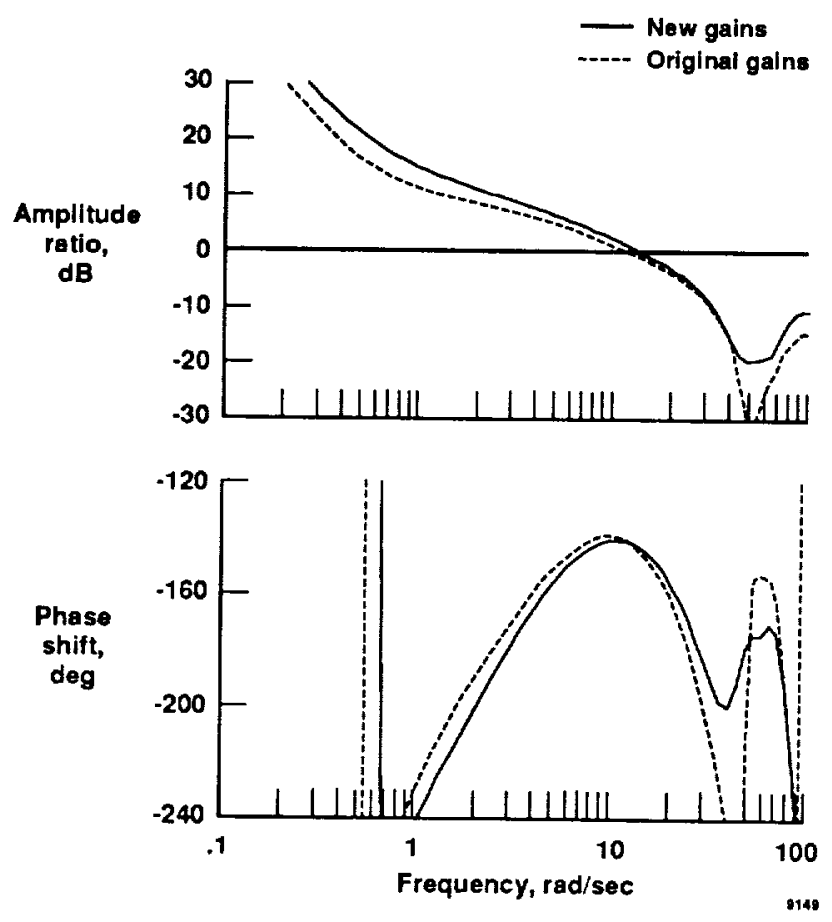

Fig. 13 Open-loop frequency response comparison between the new and original gains. 

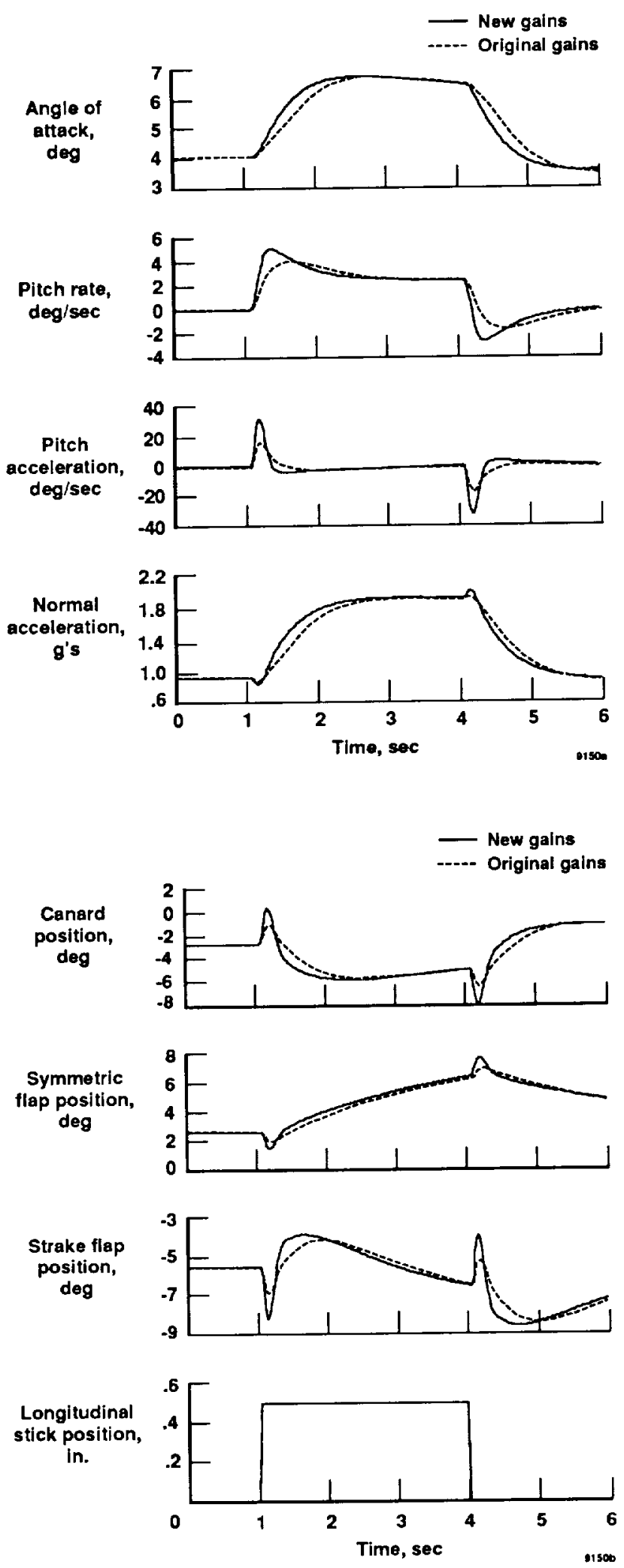

Fig. 14 Response of linear model to a pitch step input and other parameters. 

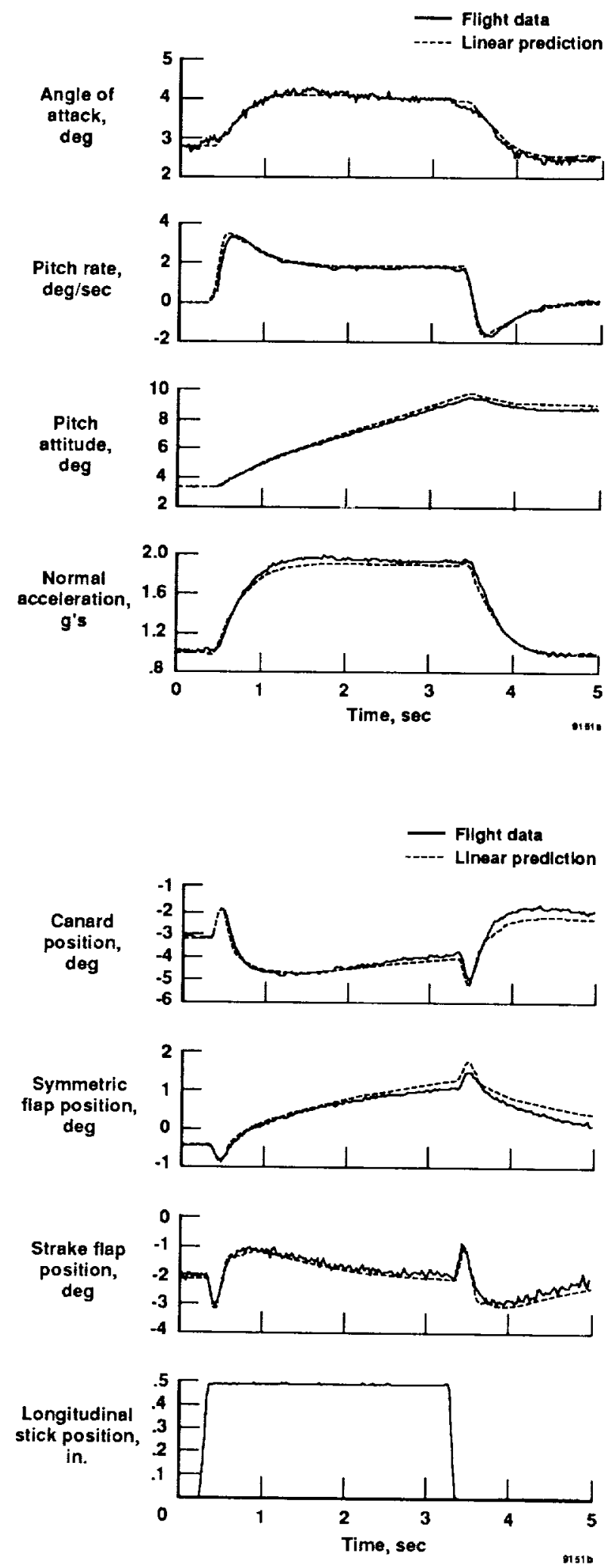

Fig. 15 Response of vchicle and linear model to pitch step with new gains. 


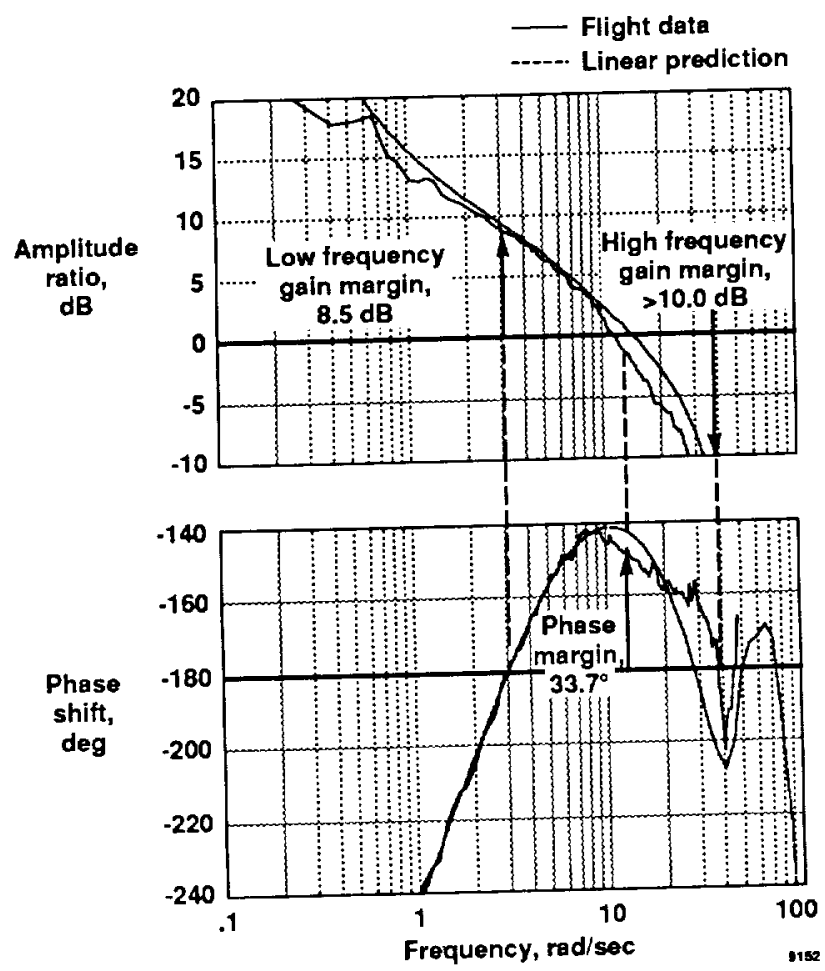

Fig. 16 Open-loop frequency response transfer function after gain change.
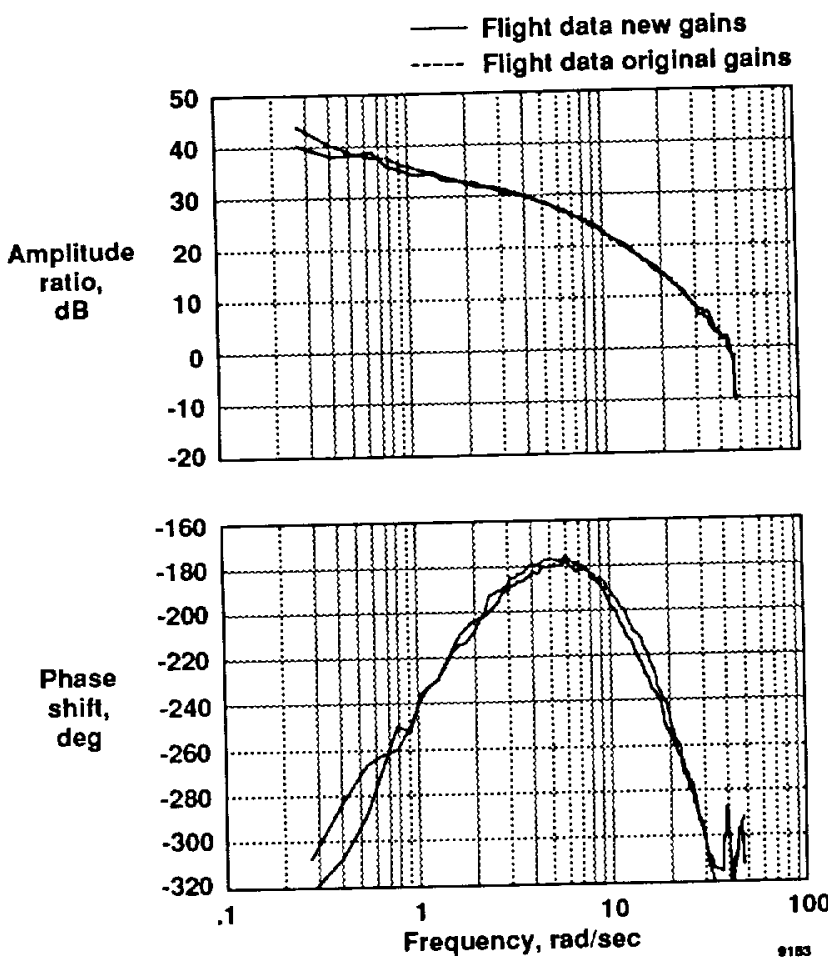

Fig. 17 Pitch rate due to $e$ transfer function before and after gain change. 

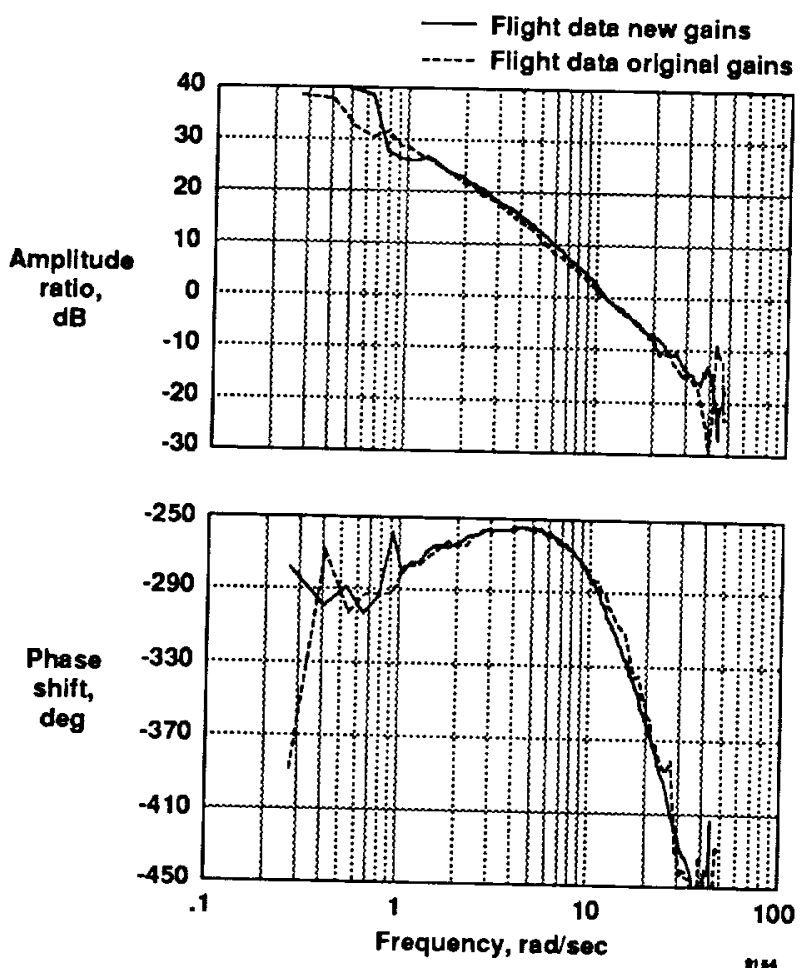

Fig. 18 Normal acceleration due to $e$ transfer function before and after gain change.
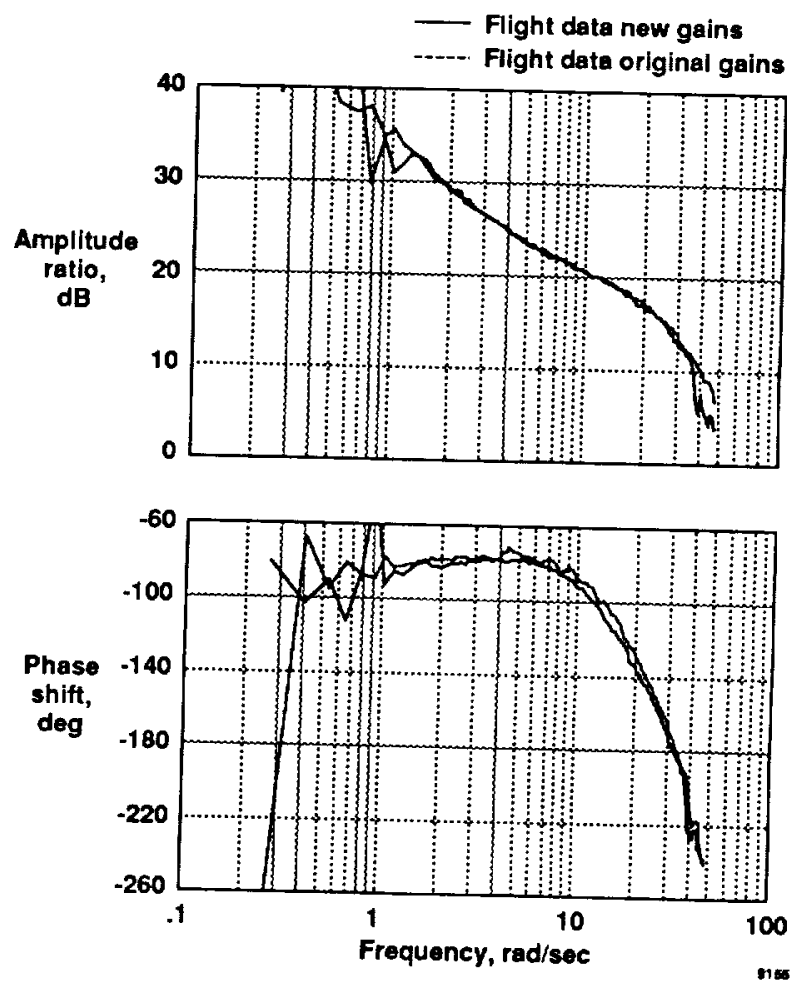

Fig. 19 Canard position due to $e$ transfer function before and after gain change. 


\begin{tabular}{|c|c|c|c|c|}
\hline \multicolumn{5}{|c|}{ Report Documentation Page } \\
\hline $\begin{array}{l}\text { 1. Report No. } \\
\text { NASA TM-4142 }\end{array}$ & \multicolumn{2}{|c|}{ 2. Government Accession No. } & \multicolumn{2}{|c|}{ 3. Recipient's Catalog No. } \\
\hline \multicolumn{3}{|l|}{ 4. Title and Subtitle } & \multicolumn{2}{|c|}{$\begin{array}{l}\text { 5. Report Date } \\
\text { September } 1989\end{array}$} \\
\hline \multicolumn{3}{|c|}{$\begin{array}{l}\text { A Design Procedure for the Handling Qualities Optimization } \\
\text { of the X-29A Aircraft }\end{array}$} & \multicolumn{2}{|c|}{ 6. Performing Organization Code } \\
\hline \multirow{2}{*}{\multicolumn{3}{|c|}{$\begin{array}{l}\text { 7. Author(s) } \\
\text { John T. Bosworth and Timothy H. Cox }\end{array}$}} & \multicolumn{2}{|c|}{$\begin{array}{l}\text { 8. Performing Organization Report No. } \\
\text { H-1548 }\end{array}$} \\
\hline & & & \multirow{2}{*}{\multicolumn{2}{|c|}{$\begin{array}{l}\text { 10. Work Unit No. } \\
\text { RTOP 533-02-51 } \\
\end{array}$}} \\
\hline \multicolumn{3}{|c|}{ 9. Performing Organization Nome and Address } & & \\
\hline \multirow{2}{*}{\multicolumn{3}{|c|}{$\begin{array}{l}\text { NASA Ames Research Center } \\
\text { Dryden Flight Research Facility } \\
\text { P.O. Box } 273 \text {, Edwards, CA } 93523-5000\end{array}$}} & \multicolumn{2}{|c|}{ 11. Contract or Grant No. } \\
\hline & & & \multicolumn{2}{|c|}{ 13. Type of Report and Period Covered } \\
\hline \multicolumn{3}{|c|}{ 12. Sponsoring Agency Nome and Address } & \multicolumn{2}{|c|}{ Technical Memorandum } \\
\hline \multicolumn{3}{|c|}{$\begin{array}{l}\text { National Aeronautics and Space Administration } \\
\text { Washington, DC } 20546\end{array}$} & \multicolumn{2}{|c|}{ 14. Sponsoring Agency Code } \\
\hline \multicolumn{5}{|c|}{ 15. Supplementary Notes } \\
\hline \multicolumn{5}{|c|}{$\begin{array}{l}\text { Prepared as AIAA paper } 89-3428 \text { for presentation at the Guidance, Navigation, and Control Conference, } \\
\text { Boston, Massachusetts, August } 14-16,1989 .\end{array}$} \\
\hline \multicolumn{5}{|l|}{ 16. Abstract } \\
\hline \multicolumn{5}{|c|}{$\begin{array}{l}\text { A design technique for handling qualities improvement was developed for the X-29A aircraft. As with any } \\
\text { new aircraft, the X-29A control law designers were presented with a relatively high degree of uncertainty } \\
\text { in their mathematical models. The presence of uncertainties, and the high level of static instability of the } \\
\text { X-29A caused the control law designers to stress stability and robustness over handling qualities. During } \\
\text { flight test, the mathematical models of the vehicle were validated or corrected to match the vehicle dynamic } \\
\text { behavior. The updated models were then used to fine tune the control system to provide fighter-like han- } \\
\text { dling characteristics. A design methodology was developed which works within the existing control system } \\
\text { architecture to provide improved handling qualities and acceptable stability with a minimum of cost in both } \\
\text { implementation as well as software verification and validation. }\end{array}$} \\
\hline \multirow{2}{*}{\multicolumn{2}{|c|}{$\begin{array}{l}\text { 17. Key Words (Suggested by Author(s)) } \\
\text { Control system; Design procedure; Handling } \\
\text { qualities; Neal-Smith criterion; Optimization; } \\
\text { Stability; X-29A }\end{array}$}} & \multirow{2}{*}{\multicolumn{3}{|c|}{$\begin{array}{l}\text { 18. Distribution Statement } \\
\text { Unclassified - Unlimited }\end{array}$}} \\
\hline & & & & \\
\hline $\begin{array}{l}\text { 19. Security Classif. (of this report) } \\
\text { Unclassified }\end{array}$ & $\begin{array}{r}\text { 20. Security Classi } \\
\text { Unclassi }\end{array}$ & his pagel & $\begin{array}{c}\text { 21. No. of pages } \\
24\end{array}$ & $\begin{array}{r}\text { 22. Price } \\
\mathrm{A} 02\end{array}$ \\
\hline
\end{tabular}


$-$ 
$-$ 
$=$ 

National Aeronautics ant

Space Administration

Code NTT-4

Washington, D.C. 20546.0001

Offeial Eusines:

Penaity ior Private Use, $\$ 300$

non

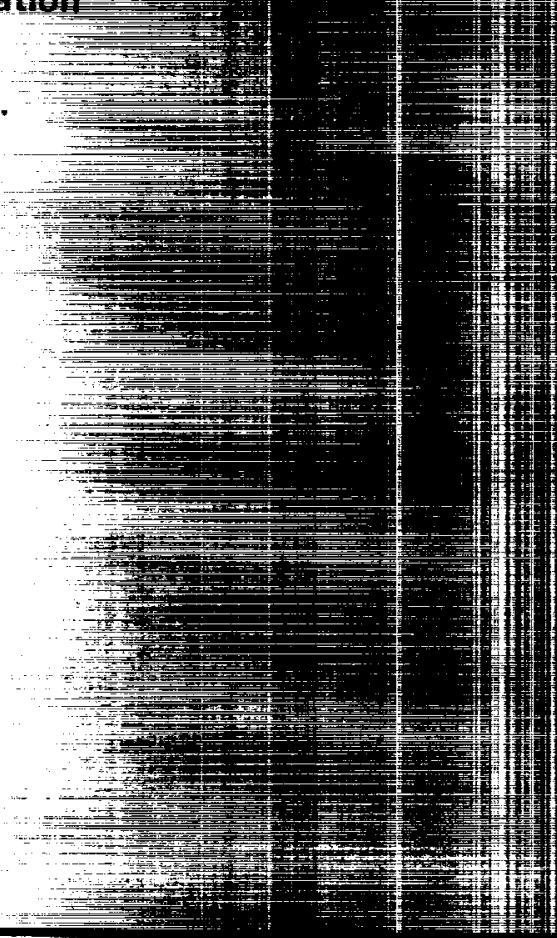

in
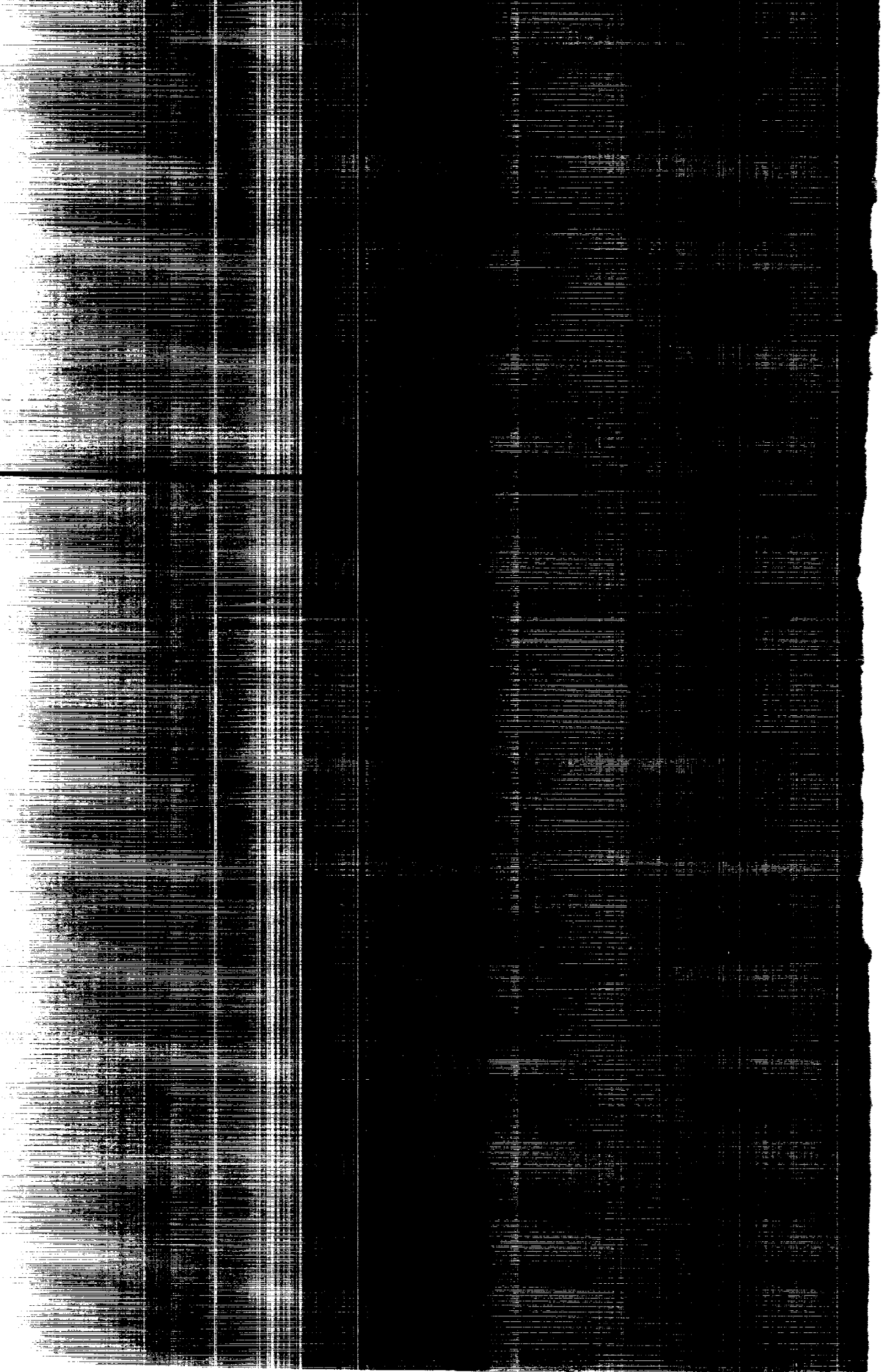